\title{
Crescimento e qualidade de mudas de baru em reposta a hidroretentor e água magnetizada
}

Growth and quality of baru seedlings in response to hydro retentor and magnetized water

\author{
J. P. P. Mendes ${ }^{1}$; A. M. Amaral ${ }^{1 *}$; M. A. S. Verssiani ${ }^{1}$; M. Â. C. M. Santos ${ }^{2}$ \\ ${ }^{I}$ Departamento de Hidráulica e Irrigação, Instituto Federal do Norte de Minas Gerais, Campus Arinos, 38680-000, \\ Arinos-Minas Gerais, Brasil \\ ${ }^{2}$ Núcleo de Engenharia de Água no Solo, Universidade Federal do Recôncavo da Bahia, 44380-000, Cruz das Almas- \\ Bahia, Brasil
}

*alisson.amaral@ifnmg.edu.br

(Recebido em 28 de agosto de 2020; aceito em 13 de novembro de 2020)

\begin{abstract}
O baru (Dipteryx alata Vogel) é uma espécie nativa do Cerrado de usos múltiplos. O objetivo desse trabalho foi verificar a influência da associação entre doses de hidroretentor e tipos de água de irrigação no crescimento e na qualidade de mudas de baru. O delineamento experimental utilizado foi o de blocos ao acaso $5 \times 2 \times 5$, com 5 repetições, sendo 5 doses de hidroretentor $\left(0,2,4,6,8 \mathrm{~g} \mathrm{~L}^{-1}\right.$ - DH), 2 águas de irrigação (normal - AN e magnetizada - AM) e 5 épocas de avaliação (15, 30, 45, 60, 75 e 90 dias após a emergência - DAE). A unidade experimental era composta de 4 mudas, cultivadas em substrato comercial sob tubetes de $120 \mathrm{~cm}^{3}$ de capacidade. $\mathrm{O}$ crescimento foi avaliado por características morfológicas (altura de planta- AP, diâmetro de caule - DC e número de folhas - NF, em intervalos quinzenais) e por produção de matéria seca (matérias secas de raiz, caule e folhas aos $90 \mathrm{DAE}$ ). As matérias secas foram usadas para estimar as razões de matéria seca. A qualidade foi determinada pelo Índice de Qualidade de Dickson (IQD). Observou-se que o crescimento em AF e NF foram limitados, enquanto que DC aumentou linearmente com o tempo. A associação entre DH e AM reduzem a AP, mas compensam no NF. A não diferença observada nas matérias secas, razões de matérias secas e IQD foram atribuídas à plasticidade fenotípica do baru. DH acima de 0,78 $\mathrm{g} \mathrm{L}^{-1}$ não influenciam expressivamente no sistema radicular devido a limitação do tubete de $120 \mathrm{~cm}^{3}$.

Palavras-chave: Dipteryx alata Vogel., magnetização, hidrogel
\end{abstract}

The baru (Dipteryx alata Vogel) is a species native to the Cerrado of multiple uses. The objective of this work was to verify the influence of the association between doses of hydro retentor and types of irrigation water in growth and quality of baru seedlings. The experimental design used was a randomized $5 \times 2 \times 5$ block, with 5 replications, with 5 doses of hydro retentor $\left(0,2,4,6,8 \mathrm{~g} \mathrm{~L}^{-1}-\mathrm{DH}\right), 2$ irrigation waters (normal - AN and magnetized - AM) and 5 evaluation periods (15, 30, 45, 60, 75 and 90 days after emergency - DAE). The experimental unit was composed of 4 seedlings, grown on a commercial substrate under tubes of $120 \mathrm{~cm}^{3}$ of capacity. Growth was evaluated by morphological characteristics (plant height - AP, stem diameter - DC and number of leaves - NC, every two weeks) and by dry matter production (root, stem and leaf dry matter at 90 DAE). Dry matter was used to estimate dry matter ratios. Quality was determined by the Dickson Quality Index (IQD). It was observed that the growth in AF and NF were limited, while DC increased linearly with time. The association between DH and AM reduces AP, but compensates for NF. The non-difference observed in dry matter, dry matter ratio and IQD were attributed to the baru's phenotypic plasticity. DH above $0.78 \mathrm{~g} \mathrm{~L}^{-1}$ do not significantly influence the root system due to the limitation of the $120 \mathrm{~cm}^{3}$ tube.

Keywords: Dipteryx alata Vogel., magnetization, hydrogel

\section{INTRODUÇÃO}

O Cerrado é considerado o segundo maior bioma da América do Sul, ocupando aproximadamente $23 \%$ do território brasileiro, com uma flora diversificada, sendo o Baru (Dipteryx alata Vogel) uma frutífera nativa de usos múltiplos com elevado interesse ambiental, socioeconômico e alimentar (animal e humano), principalmente devido a qualidade nutricional e do óleo da amêndoa produzido [1, 2, 3].

As modificações sofridas pelo Cerrado nas duas últimas décadas, em função do aumento da produção agrícola, da pecuária e da indústria, induziram iniciativas de conservação, recomposição 
e uso sustentável de áreas desse bioma, nesse sentido, o interesse dessa espécie é justificado, principalmente, pela rápida germinação de sementes e crescimento da muda. Todavia, para o sucesso de projetos de conservação e recuperação ambiental a escolha de espécies adaptadas às condições edafoclimáticas locais e da utilização de mudas de boa qualidade é determinante $[4,5$, $6]$.

A produção de mudas para plantios comerciais ou recuperação de áreas degradas, por exemplo, dependem de diversos fatores para que estas externem todo o seu potencial produtivo e de crescimento [7] a citar, dentre eles, o substrato usado e a frequência de irrigação, fatores estes importantes para a eficiente disponibilidade de água e nutrientes na emergência e no desenvolvimento das mudas $[8,9]$.

Entre as tecnologias disponíveis para o abastecimento de água às plantas estão os condicionadores de umidade de solo, também conhecidos como hidroretentores, hidroabsorventes, hidrogel, dentre outros. O uso do polímero hidroretentor favorece o aumento da capacidade de retenção e armazenamento de água em substratos, com extração gradual ao longo do tempo pela planta e se torna uma alternativa para reduzir a frequência de irrigação na produção de mudas [10, 11], além disso, condicionam a redução da perda de nutrientes por percolação e lixiviação e melhoram a aeração do solo $[12,13,14,15]$.

A frequência de irrigação na produção de mudas sem estudos prévios, pode gerar problemas como lixiviação, excesso ou deficiência hídrica, gasto energético com bombeamento de sistemas de irrigação e demanda constante de responsável técnico para tal prática.

É comum na literatura trabalhos que reportam frequências de irrigação e frações de reposição diversas, com variação de uma irrigação diária até doze vezes ao dia em espécies distintas [10, 16, $17,18,19]$ entretanto, torna-se inviável uma frequência reduzida associada ao uso de hidrogel, pois, segundo [20] o custo de produção e plantio com uso do hidrogel é menor em estações secas. Ou seja, na produção de mudas em substratos comerciais, parece inconsistente o uso de doses de polímero hidroabsorvente com irrigações frequentes ou diárias visando manter a umidade elevada.

O suprimento de água tratada magneticamente pode auxiliar na viabilidade da utilização de irrigações menos constantes, haja visto as melhorias reportadas nos cultivos como: aumento na eficiência de uso de água, crescimento morfológico, redução de pH do meio, disponibilidade de nutrientes, entre outros [21, 22, 23], porém, ainda são necessários mais estudos para identificar as alterações físicas, químicas e suas lacunas conceituais sobre os mecanismos que modificam a fisiologia de plantas irrigadas com este tipo de água [24].

Pelo exposto, objetivou-se nesse trabalho avaliar a influência da irrigação com água magnetizada associada a polímero hidroretentor no crescimento e na qualidade de mudas de baru produzidas em ambiente protegido.

\section{MATERIAL E MÉTODOS}

$\mathrm{O}$ estudo foi conduzido em ambiente protegido localizado na área experimental do Instituto

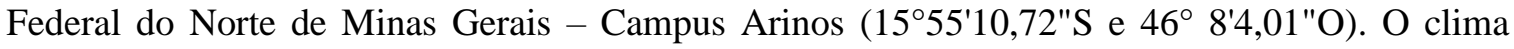
predominante é o subtropical úmido com inverno seco e verão chuvoso, do tipo "Aw" pela classificação de Köppen-Geiger. O delineamento experimental utilizado foi o de blocos ao acaso (DBC) com tratamentos em fatorial triplo constituídos de 5 doses de polímero hidroretentor $(0,2$, 4, 6 e $8 \mathrm{~g} \mathrm{~L}^{-1}$ ) - fator A, 2 tipos de água de irrigação (normal e magnetizada) - fator B e 6 épocas de avaliação $(15,30,45,60,75$ e 90 dias após a emergência - DAE) - fator C, com 5 repetições.

Cada unidade experimental era composta de 4 plantas de baru cultivadas em substrato comercial da empresa Bioplant, este depositado em tubetes com volume de $120 \mathrm{~cm}^{3}$, de forma a manter uma densidade de $0,150 \mathrm{~g} \mathrm{~cm}^{-3}$. Segundo informações do fabricante, o substrato utilizado é composto de uma mistura de turfa de sphagnum, fibra de coco, casca de arroz, casca de pinus, vermiculita, gesso agrícola, carbonato de cálcio, magnésio, termofosfato magnesiano e aditivos.

O polímero hidroretentor usado como condicionador era da fabricante Hydroplan-EB, considerado um condicionador de solo absorvente de água constituído de um misto de Copolímero de Acrilamida e Acrilato de Potássio, com aparência granular de cor branca, tamanho de partícula 
entre 0,5 a $3 \mathrm{~mm}$, aniônico, com $100 \%$ de ingrediente ativo sólido, $10 \%$ de umidade, $0,8 \mathrm{~g} \mathrm{~cm}^{-1} \mathrm{de}^{2}$ densidade volumétrica e insolúvel em água.

Os tipos de água usados na irrigação foram aquelas provenientes de fonte de abastecimento (água normal - AN) e água normal após magnetização (água magnetizada - AM). Para armazenamento dos tipos de água utilizou-se 2 reservatórios de PVC distintos, ambos com capacidade de $250 \mathrm{~L}$. O processo de magnetização ocorreu com a deposição de um magnetizador Sylocimol Rural, modelo Rural 3000 da fabricante Timol Indústria e Comércio de Produtos Magnéticos, em um dos reservatórios. Este permaneceu imerso constantemente, tomando-se o cuidado para que, em momento de abastecimento do reservatório, a água fosse submetida a magnetização por um período superior a 10 horas.

De acordo com a fabricante, o modelo usado é composto por ímãs alternados revestidos de proteção em aço inoxidável capazes de submeter a água a um campo magnético de 3860 Gaus, com alternância de polaridade na ordem de $60 \mathrm{~Hz}$. Este possui ímãs permanentes orientados, com constante emissão de fluxo ionizante de elétrons direcionados que agem na quebra dos clusters de água de abastecimento, resultando em clusters menores.

O manejo da irrigação nas unidades experimentais era feito via monitoramento do conteúdo de água no substrato por sonda resistiva visando elevar a umidade até a máxima capacidade de retenção (capacidade de campo). A reposição hídrica ocorreu de forma manual com o auxílio de pisseta. Foram feitas irrigações diárias até os 15 DAE para que houvesse formação de stand e após esse período o turno de rega era de 2 dias para que pudesse observar efeito dos tratamentos com o polímero hidroabsorvente. Os resultados iniciais da calibração da sonda foram discutidos e publicados em [25], endossados por estudo semelhante [26].

As variáveis climáticas monitoradas no local durante o período avaliado foram a temperatura do ar $\left({ }^{\circ} \mathrm{C}\right)$ e umidade relativa $\left({ }^{\circ} \mathrm{C}\right)$ por meio do sensor DHT22 situado em abrigo meteorológico e conectado a um microcontrolador Arduino Uno, cujos dados horários foram armazenados em cartão de memória e posteriormente transferidos para laptop para processamento e análise.

Para avaliar o crescimento e desenvolvimento das mudas mensurou-se as variáveis altura de planta (AP), diâmetro de caule (DC) e número de folhas (NF) entre 15 e 90 DAE e comprimento de raiz (CR) aos 90 DAE. O acúmulo, razão e partição de fotoassimilados foram analisados pela matéria seca de raiz (MSR), matéria seca de caule (MSC), matéria seca de folha (MSF), matéria seca total (MST), razão parte aérea e sistema radicular (RPASR), razão de matéria seca de folha (RMF), razão de matéria seca de raiz (RMR) e razão de matéria seca de caule (RMC), também aos 90 DAE.

A AP foi mensurada por meio de régua graduada, o DC com auxílio de um paquímetro analógico, o número de folhas por contagem visual e o CR também por meio de régua graduada após retirada do substrato e lavagem do sistema radicular em água corrente. Para determinação das matérias secas houve a separação dos componentes raiz, caule e folha + pecíolo e após condicionadas em sacos de papel previamente identificados de acordo com os tratamentos, foram colocadas em estufa de ventilação forçada de ar à temperatura de $70^{\circ} \mathrm{C}$ por um período de 72 horas e depois submetidas à pesagem em balança de precisão com resolução de $0,001 \mathrm{~g}$.

Para avaliar a qualidade das mudas, utilizou-se o Índice de Qualidade de Dickson (IQD) calculado pela equação 1, conforme sugestão de [27]. O IQD também foi calculado para os 90 DAE.

$$
I Q D=\frac{M S T}{\left[\left(\frac{A P}{D C}\right)\right]+\left(\frac{M S P A}{M S R}\right)}
$$

Em que, IQD = Índice de qualidade de Dickson, (adimensional); MST = Massa seca total, $(\mathrm{g})$; $\mathrm{AP}=$ Altura de planta, $(\mathrm{cm}) ; \mathrm{DC}=$ Diâmetro de caule, $(\mathrm{mm}) ; \mathrm{MSPA}=$ Matéria seca da parte aérea, calculada pela soma da matéria seca de caule e folha, (g) e MSR = Matéria seca da raiz, (g).

Após tabulados, os dados foram submetidos à análise de variância com auxílio do software Sisvar v.5.7 [28]. que, quando significativos, os fatores quantitativos foram avaliados por regressão 
múltipla e os qualitativos pelo teste de Tukey a 5\% de probabilidade. O software Sigmaplot v.11 foi usado para ajustar as funções de crescimento que melhor se ajustaram de acordo com [29]. Para melhor interpretação dos resultados foram geradas figuras e tabelas por meio de planilha de cálculo.

\section{RESULTADOS E DISCUSSÃO}

Pelo resumo da análise de variância (Tabela 1) observa-se que houve diferenças significativas com efeito isolado da época de avaliação (E) e também a interação entre as doses de hidroretentor (H) e o tipo de água de irrigação (A) em todas as variáveis de crescimento.

Tabela 1: Resumo da análise de variância em variáveis de crescimento de Dipteryx alata Vog.

\begin{tabular}{ccccc}
\hline \multirow{2}{*}{ Fonte de variação } & GL & \multicolumn{3}{c}{ Quadrados médio } \\
\cline { 3 - 5 } & & Altura de planta & Diâmetro de caule & Número de folhas \\
\hline Bloco & 4 & $8,37^{* *}$ & $0,51^{* *}$ & $0,60^{* *}$ \\
Dose de Hidroretentor (H) & 4 & $20,45^{* *}$ & $0,12^{\mathrm{ns}}$ & $2,01^{* *}$ \\
Tipo de Água (A) & 1 & $0,69^{\mathrm{ns}}$ & $0,26^{\mathrm{ns}}$ & $0,03^{\mathrm{ns}}$ \\
Época de avaliação (E) & 5 & $59,68^{* *}$ & $15,39^{* *}$ & $54,05^{* *}$ \\
H x A & 4 & $8,68^{* *}$ & $0,24^{* *}$ & $0,56^{* *}$ \\
H x E & 20 & $0,36^{\mathrm{ns}}$ & $0,05^{\mathrm{ns}}$ & $0,14^{\mathrm{ns}}$ \\
A x E & 5 & $0,35^{\mathrm{ns}}$ & $0,01^{\mathrm{ns}}$ & $0,04^{\mathrm{ns}}$ \\
H x A x E & 20 & $0,16^{\mathrm{ns}}$ & $0,02^{\mathrm{ns}}$ & $0,05^{\mathrm{ns}}$ \\
Resíduo & 236 & 1,45 & 0,07 & 0,11 \\
\hline CV (\%) & & 9,33 & 6,00 & 8,49
\end{tabular}

GL - Grau de liberdade, CV - Coeficiente de variação, * - Significativo a 1\% pelo teste de Tukey, ** Significativo a $5 \%$ pelo teste de Tukey, ${ }^{\text {ns }}-$ Não significativo.

De acordo com os modelos matemáticos de ajuste da Figura 1 verifica-se que a $\mathrm{AP}$ e o NF atingiram valores máximos de $13,7 \mathrm{~cm}$ e 5 folhas aos 80 e 74 dias, respectivamente, enquanto que o DC aumentou linearmente durante todo o período avaliado, perfazendo um incremento total de $1,48 \mathrm{~mm}$.

É possível que o baru em fase de muda tenha limitado o crescimento em AP e NF para favorecer a translocação dos fotoassimilados produzidos para o componente de sustentação (caule). Honorio et al. (2019) [30] salientam que o DC é um excelente indicador da capacidade de sobrevivência de uma muda e que seu aumento favorece o equilíbrio do crescimento da parte aérea da planta, além disso, para [12] maiores diâmetros de caule reduzem a possibilidade de tombamento após o transplantio. 

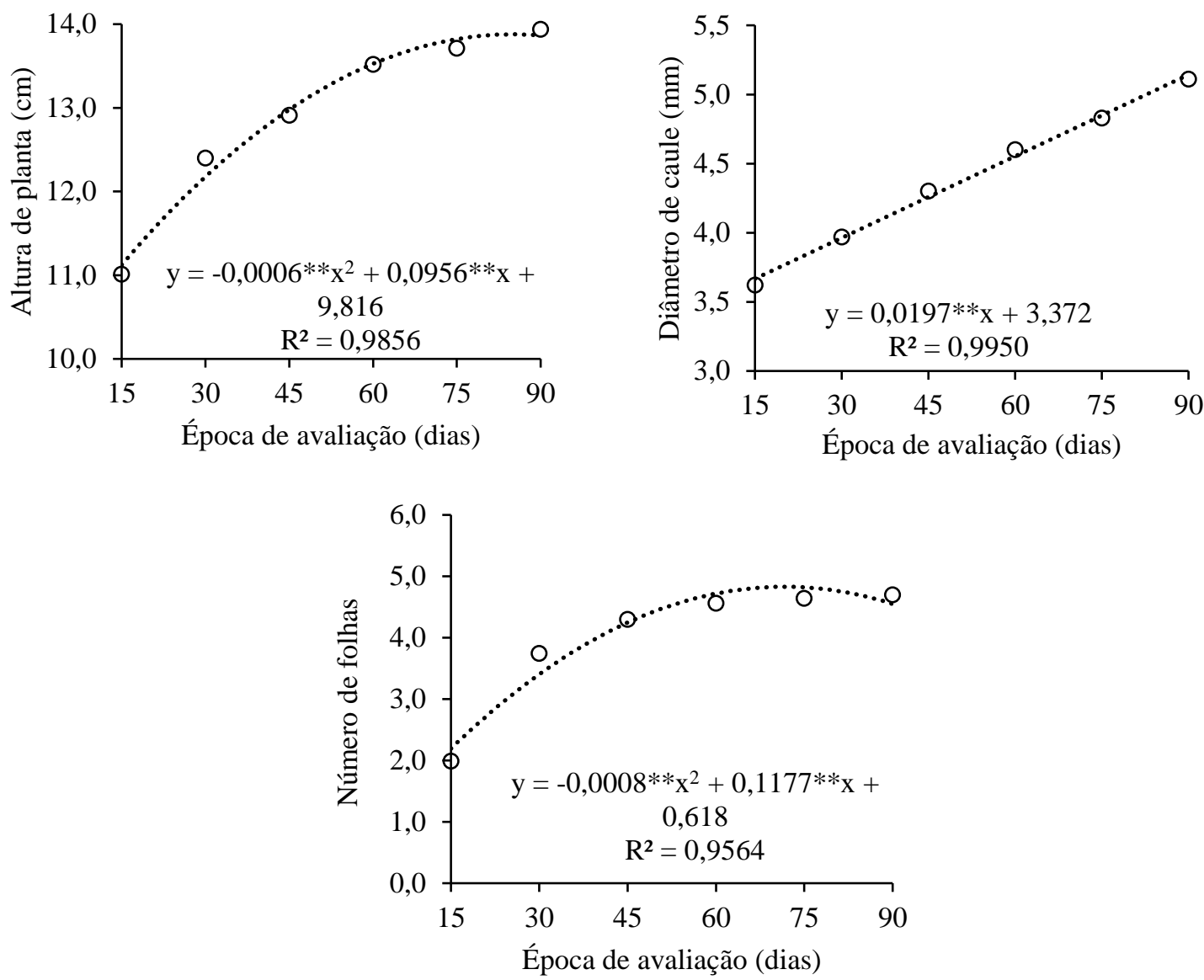

Figura 1: Altura de planta, diâmetro de caule e número de folhas de mudas de Dipteryx alata Vog. em função da época de avaliação.

Na Figura 2 observam-se as curvas ajustadas para o desdobramento da interação das doses de hidroretentor dentro de cada tipo de água de irrigação nas variáveis AP e NF. Considerando a variável AP, observou-se um crescimento máximo de $13,6 \mathrm{~cm}$ para uma dose estimada de $1,2 \mathrm{~g} \mathrm{~L}^{-}$ ${ }^{1}$, com posterior decréscimo a partir dessa dose, quando usada água magnetizada na irrigação das mudas. Já para irrigação com água normal, o aumento das doses de hidroretentor resultaram em decréscimos lineares na AP, totalizando $9,8 \%$, porém com ajuste mediano $\left(R^{2}=0,5528\right)$.
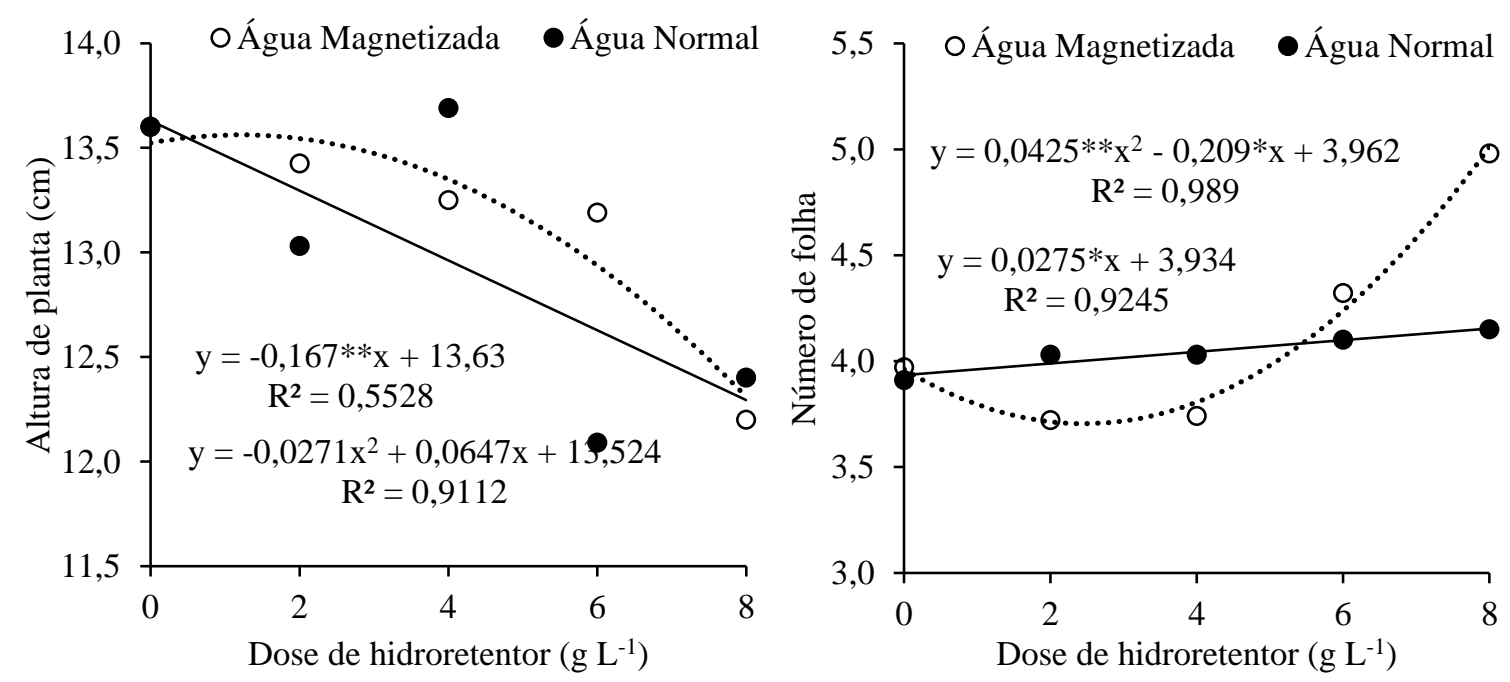

Figura 2: Desdobramento da interação da dose de hidroretentor para cada tipo de água nas variáveis altura de planta e número de folha de mudas de Dipteryx alata Vog. 
A elevação das doses do polímero hidroabsorvente pode ter favorecido aumento excessivo de umidade no substrato e resultar na supressão do crescimento em AP, por reduzir a aeração no sistema radicular devido à expansão do polímero umedecido, o que já foi reportado por [31] em estudos prévios. Para esses autores a água disponível às plantas em substratos comerciais já é considerada acima do ideal, mesmo sem a adição de hidroretentor, e que a elevação desse polímero reduz o espaço de aeração do substrato, o que corrobora com o exposto. Entretanto, vê-se também que a água magnetizada foi capaz de reduzir esse efeito e até favorecer o aumento da AP para doses menores do que $1,2 \mathrm{~g} \mathrm{~L}^{-1}$.

Já para o NF ocorre situação inversa, com aumento linear em função das doses de hidroretentor quando irrigadas com água normal, entretanto, o incremento total é de apenas 5,59\% se comparado ao incremento com uso de água magnetizada. Quando usada água magnetizada, esse aumento ocorre para doses maiores que 2,46 $\mathrm{g} \mathrm{L}^{-1}$ com incremento total de $35,22 \%$ a partir dessa dose, ou seja, um ganho em NF mais expressivo do que o estimado para mudas submetidas à irrigação com água normal. Percebe-se que a interação dos fatores usados influencia de formas diversas nas variáveis de crescimento.

Considerando que as folhas são as estruturas mais importantes de um vegetal por serem os aparatos fotossintéticos e que AP serve para erguer as folhas até a luz [32], principalmente em condições de competição de plantas, o uso da água magnetizada na irrigação associada ao aumento de doses de hidrogel implica na redução da AP, mas com consequente compensação em NF de Dipteryx alata Vog.

Ainda são incipientes ou inexistentes estudos sobre a interação entre doses de hidroretentor e água magnetizada em espécies arbóreas em fase de muda, principalmente em substratos comerciais, entretanto, é possível que os resultados observados sejam derivados das inúmeras alterações nas propriedades físico-químicas da água e do substrato $(\mathrm{pH}$, condutividade elétrica, sais dissolvidos, desbalanço de nutrientes) e também nos fatores fisiológicos relacionados ao crescimento, como enzimas e hormônios [23, 31, 33, 34, 35], sendo assim, estudos mais específicos são necessários para inferir com mais propriedade sobre o resultados expostos.

Apesar da interação entre os fatores ( $\mathrm{H}$ x A) não foi possível ajustar nenhum modelo matemático no DC, motivo pelo qual não foi discutido nesse trabalho.

No desdobramento da interação do tipo de água de irrigação para cada dose de hidroretentor houve diferença significativa apenas para as doses de 2 e $6 \mathrm{~g} \mathrm{~L}^{-1}$ na AP e de 0 e $4 \mathrm{~g} \mathrm{~L}^{-1}$ no DC, conforme a Tabela 2. Para as menores doses $\left(0,2 \mathrm{e} 4 \mathrm{~g} \mathrm{~L}^{-1}\right)$ observou-se que a irrigação com água normal propiciou aumentos na ordem de 7,86\% (AP); 4,64\% e 4,35\% no DC, respectivamente. Já na dose de $6 \mathrm{~g} \mathrm{~L}^{-1}$ a água magnetizada estimulou um crescimento de 9,10\% na AP.

Tabela 2: Desdobramento da interação do tipo de água para cada dose de hidroretentor nas variáveis altura de planta e diâmetro de caule de Dipteryx alata Vog.

\begin{tabular}{|c|c|c|c|c|}
\hline \multirow{3}{*}{ Tipo de água de irrigação } & \multicolumn{2}{|c|}{ Altura de planta $(\mathrm{cm})$} & \multicolumn{2}{|c|}{ Diâmetro de caule (mm) } \\
\hline & \multicolumn{4}{|c|}{ Dose de hidroretentor $\left(\mathrm{g} \mathrm{L}^{-1}\right)$} \\
\hline & 2,00 & 6,00 & 0,00 & 4,00 \\
\hline Magnetizada & $12,08 \mathrm{~b}$ & $13,19 \mathrm{a}$ & $4,31 \mathrm{~b}$ & $4,36 \mathrm{~b}$ \\
\hline Normal & $13,03 \mathrm{a}$ & $12,09 \mathrm{~b}$ & $4,51 \mathrm{a}$ & $4,55 \mathrm{a}$ \\
\hline
\end{tabular}

No resumo da análise de variância na Tabela 3, observa-se que houve efeito isolado das doses de hidroretentor apenas no comprimento de raiz (CR). Para as matérias secas, razões de matérias secas e IQD os tratamentos não resultaram em nenhuma diferença estatística significativa.

Pelas médias obtidas na MSR, MSC, MSF e RPASR percebe-se que houve maior aporte de fotoassimilados no caule, seguido de folha e por último em sistema radicular, ou seja, nas condições experimentais do estudo as mudas de baru tiveram um maior desenvolvimento da parte aérea, mesmo que os tratamentos não tenham surtido efeito nessas variáveis. De forma quantitativa, do total de matéria seca produzida houve uma partição e acúmulo de fotoassimilados na ordem de $18 \%$ para folhas (RMF), 65\% para caule (RMC) e 17\% em raiz (RMR). 
Tabela 3: Resumo da análise de variância para o comprimento de raiz, matérias secas, razões de matérias secas e qualidade de mudas de Dipteryx alata Vog.

\begin{tabular}{cccccccccccc}
\hline \multirow{2}{*}{$\begin{array}{c}\text { Fonte de } \\
\text { Variação }\end{array}$} & $\mathrm{GL}$ & $\mathrm{CR}$ & $\mathrm{MSR}^{1}$ & $\mathrm{MSC}^{1}$ & $\mathrm{MSF}^{1}$ & $\mathrm{MST}^{1}$ & $\mathrm{RPASR}^{1}$ & $\mathrm{RMF}^{1}$ & $\mathrm{RMC}^{2}$ & $\mathrm{RMR}^{1}$ & $\mathrm{IQD}^{1}$ \\
\hline & \multicolumn{1}{c}{ (cm) } \\
\hline Bloco & 4 & $2,65^{\text {ns }}$ & $0,023^{*}$ & $0,117^{\text {ns }}$ & $0,030^{* *}$ & $0,173^{* *}$ & $0,077^{\text {ns }}$ & $0,0001^{\text {ns }}$ & $0,0020^{\text {ns }}$ & $0,0002^{\text {ns }}$ & $0,021^{\text {ns }}$ \\
Hidro (H) & 4 & $2,75^{* *}$ & $0,020^{\text {ns }}$ & $0,051^{\text {ns }}$ & $0,002^{\text {ns }}$ & $0,074^{\text {ns }}$ & $0,039^{\text {ns }}$ & $0,0001^{\text {ns }}$ & $0,0000^{\text {ns }}$ & $0,0001^{\text {ns }}$ & $0,011^{\text {ns }}$ \\
Água (A) & 1 & $0,32^{\text {ns }}$ & $0,008^{\text {ns }}$ & $0,010^{\text {ns }}$ & $0,013^{\text {ns }}$ & $0,010^{\text {ns }}$ & $0,148^{\text {ns }}$ & $0,0001^{\text {ns }}$ & $0,0000^{\text {ns }}$ & $0,0006^{\text {ns }}$ & $0,005^{\text {ns }}$ \\
H x A & 4 & $0,51^{\text {ns }}$ & $0,007^{\text {ns }}$ & $0,014^{\text {ns }}$ & $0,005^{\text {ns }}$ & $0,026^{\text {ns }}$ & $0,027^{\text {ns }}$ & $0,0000^{\text {ns }}$ & $0,0010^{\text {ns }}$ & $0,0001^{\text {ns }}$ & $0,005^{\text {ns }}$ \\
Resíduo & 36 & 0,62 & 0,008 & 0,044 & 0,009 & 0,052 & 0,047 & 0,0001 & 0,0010 & 0,0002 & $0,006^{\text {ns }}$ \\
\hline CV (\%) & 4,89 & 5,96 & 8,21 & 6,15 & 7,35 & 8,89 & 1,08 & 6,69 & 1,34 & $6,35 \%$ \\
\hline Média & 16,21 & 1,47 & 5,70 & 1,58 & 8,75 & 5,11 & 0,18 & 0,65 & 0,17 & 1,15 \\
\hline
\end{tabular}

GL - Grau de liberdade, CV - Coeficiente de variação, * - Significativo a 1\% pelo teste de Tukey, ** - Significativo a 5\% pelo teste de Tukey, ${ }^{\text {ns }}$ - Não significativo, Hidro - Dose de hidroretentor, Água - Tipo de água, CR - Comprimento de raiz, MSR - Matéria seca de raiz, MSC - Matéria seca de caule, MSF - Matéria seca de folha, MST - Matéria seca total, RPASR - Razão parte aérea e sistema radicular, RMF - Razão de matéria seca foliar, RMC - Razão de matéria seca de caule, RMR - Razão de matéria seca de raiz, ${ }^{1}$ - Dados transformados por $\sqrt{y+1}$

É esperado e importante que mais fotoassimilados sejam usados na parte aérea da planta, favorecendo maiores razões ramos/raízes e a formação de tecidos foliares, principalmente a iniciação de novas folhas apicais, maior crescimento foliar e tamanho final de folhas, bem como maior ramificação (número de ápices ativos) [29]. Para esses autores, dentro de um conjunto de condições como temperatura do ar e do solo, luz, disponibilidade de água e nutrientes a RPASR é bem estável e, quando perturbado, ocorre um crescimento compensatório reduzindo a RPASR, o que não foi observado no baru.

A não diferença observada nas matérias secas e razões de matéria seca em função dos tratamentos pode ser atribuída à elevada plasticidade fenotípica da Dipteryx alata Vog resultando na aclimatação e adaptabilidade das mudas [4, 36, 37, 38].

Diferentemente deste trabalho, [39] verificaram que doses crescentes de polímero hidroabsorvente $\left(0,2,4,6,8 \mathrm{~g} \mathrm{~L}^{-1}\right)$ reduziram linearmente a MST e a MSR de Anadenanthera peregrina (L.) SPEG por favorecer um excesso de umidade no substrato. Já [13] verificaram uma elevada variabilidade na MST, MSR e na massa seca da parte aérea (MSPA) de Eucalyptus dunnii a depender da dose de polímero utilizada, com crescimento máximo e posterior decréscimo nas variáveis. Esses autores ainda evidenciam que a presença de turfa de sphagnum nos substratos comerciais, associados a elevadas doses de hidroretentor, promovem maiores elevações de umidade e, em certos casos, até o deslocamento das mudas nos recipientes pela expansão volumétrica do polímero.

Convém salientar que, no momento do desbaste das mudas, o polímero hidroretentor expandido pela umidade localizava-se na porção inferior do tubete, independente dos tratamentos, o que pode ter contribuído para a não identificação da umidade excessiva pelas sondas resistivas que possuem um comprimento de $6 \mathrm{~cm}$, enquanto que os tubetes perfaziam $14 \mathrm{~cm}$. Soma-se a isso o efeito da evaporação superficial do substrato.

A Figura 3 mostra a função sigmoidal ajustada para o comprimento de raiz em função das doses de hidroretentor que expressa o crescimento limitado de plantas conforme [29]. Por essa função verifica-se a maior taxa de variação no $\mathrm{CR}$ até o ponto de inflexão de $0,78 \mathrm{~g} \mathrm{~L}^{-1}$ a qual atinge 15,87 $\mathrm{cm}$, ou seja, essa dose é responsável pelo maior incremento nessa variável. A partir dela a variação é expressivamente reduzida, entretanto positiva, com um valor assintótico de 16,51 cm. 


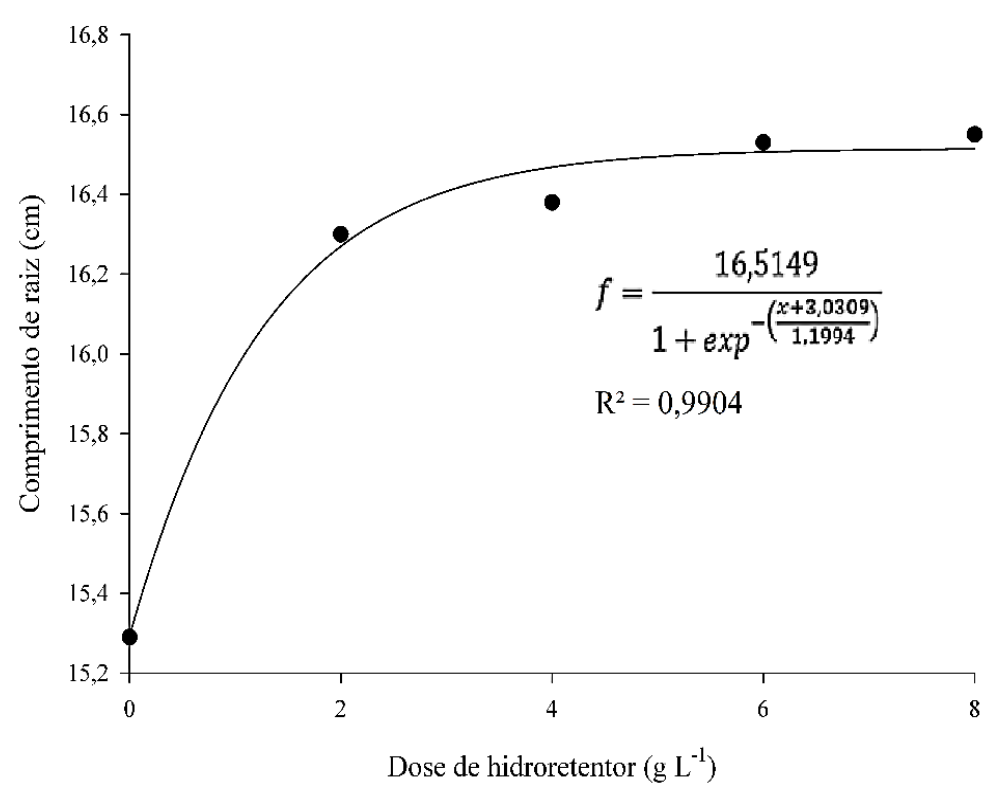

Figura 3: Comprimento de raiz em função da dose de hidroretentor em mudas de Dipteryx alata Vog.

Os resultados mostram que a elevação da dose do polímero acima de $0,78 \mathrm{~g} \mathrm{~L}^{-1}$ não resultou em crescimento expressivo do sistema radicular, possivelmente devido à limitação de espaço para seu desenvolvimento em tubetes com capacidade de $120 \mathrm{~cm}^{3}$.

Um maior crescimento de raiz em mudas de umbuzeiro (Spondias tuberosa Arruda Câmara) cultivadas em diferentes volumes de recipiente foi observado por [40] e estes sugerem que esse resultado pode estar relacionado com o maior espaço para deposição de substratos, favorecendo melhores condições para o crescimento e desenvolvimento radicular com reflexo em outras partes da planta, como a altura por exemplo. Resultados semelhantes foram reportados por [41] na produção de baruzeiro e por [42] em mudas de jabuticabeira, onde os recipientes de maiores capacidades favorecem melhores condições de desenvolvimento radicular, disponibilidade de nutrientes e consequentemente o desenvolvimento da parte aérea. Além disso, foram verificadas melhorias expressivas na condutância estomática de mudas de baru em diferentes tamanhos de recipientes, com médias maiores para mudas acondicionadas em recipientes maiores [30], o que favorece melhor desenvolvimento de todas as partes da planta (raiz, caule e folhas).

A utilização do polímero hidroretentor incorporado ao substrato na produção de mudas ainda precisa de mais estudos, tanto com aplicação em diversas espécies, quanto em condições experimentais diversas [39] e sua associação com água magnetizada é de grande relevância para o entendimento do comportamento fisiológico vegetal e da gestão do uso de água.

\section{CONCLUSÃO}

O crescimento em altura e número de folhas no baru foram limitados aos 80 dias após a emergência, enquanto que o diâmetro de caule aumentou linearmente devido ao balanço de fotoassimilados.

O uso da água magnetizada na irrigação associada ao aumento das doses de hidroretentor implicam na redução da altura de planta, porém com compensação expressiva no número de folhas que correspondem ao aparato fotossintético do baru.

A não diferença observada nas matérias secas, razões de matérias secas e Índice de Qualidade de Dickson em função dos tratamentos pode ser atribuída à elevada plasticidade fenotípica do baru, resultando na aclimatação e adaptabilidade das mudas.

Os resultados mostram que a elevação da dose do polímero acima de $0,78 \mathrm{~g} \mathrm{~L}^{-1}$ não resultou em crescimento expressivo do sistema radicular, possivelmente devido à limitação de espaço para seu desenvolvimento em tubetes com capacidade de $120 \mathrm{~cm}^{3}$. 


\section{REFERÊNCIAS BIBLIOGRÁFICAS}

1. Mota EES, Novaes CRDB, Silva LB, Chaves LJ. Structure of the phenotypic variability of fruit and seeds of Dipteryx alata vogel (Fabaceae). Rev Bras Frutic. 2020,42(5):1-11, doi: 10.1590/0100-29452020003.

2. Ferreira CM, Gabriela GH, Nepomuceno L, Cruz, VS, Araújo, EG. Caracterização botânica e cadeia produtiva da espécie Dipteryx alata Vogel. Encicl Biosfera. 2018 Mar;15(28):202-217, doi: 10.18677/EnciBio_2018B18.

3. Melo SABX, Silva FS, Melo AX, Bento TS. Cadeia produtiva do cumbaru (Dipteryx alata Vogel) em Poconé, Mato Grosso. Cad Ci Tecnol. 2017 Jan;34(1):37-58, doi: 10.35977/01041096.cct2017.v34.26292.

4. Borella DR, Souza AP, Silva AC, Felipe RTA, Silva KNC, Souza JHG. Exigências térmicas e filocrono de Dipteryx alata sob níveis de sombreamento na transição Cerrado-Amazônia. Sci Plena. 2020,16(5): 115, doi: 10.14808/sci.plena.2020.051702.

5. Santos KDG, Ferreira WM, Silva KLF, Coimbra RR, Souza CC. Germination and initial development of Dipteryx alata Vogel (Fabaceae) in two "Cerrado" areas: a step toward its use in reforestation programs. Braz J Bot. 2018;41(2):415-424, doi: 10.1007/s40415-018-0453-0.

6. Freitas ECS, Paiva HN, Leite HG, Neto SNO. Crescimento de mudas de Dipteryx alata sob adubação fosfatada e calagem. Ambiência. 2018 Mai;14(2):267-281, doi: 10.5935/ambiencia.2018.02.05.

7. Azevedo GTO, Souza AM, Azevedo GB, Teodoro PE, Sousa JRL. Influence of fertilizer and hydrogel on physicalchemical attributes of substrate for seedling production. Biosci J. 2019 Sep;35(5):1399-1407, doi: 10.14393/BJ-v35n5a2019-42267.

8. Tagatiba SD, Silva AG, Penchel Filho RM, Reis EF, Ramos KA. Disponibilidade hídrica e doses de polímero hidrorretentor na produção de mudas clonais de eucalipto. Rev Eng Agric. 2019;27(4):359-369, doi: 10.13083/reveng.v27i4.938.

9. Silva GO, Aguiar BAC, Terra DCV, Sousa RM, Fonseca EF, Souza PB. Umidade do substrato e desempenho da emergência da espécie Anadenanthera peregrina (L) speg. Magistra. 2019;30:336-341.

10. Bernadino LT, Bonomo R, Souza JM. Desenvolvimento inicial de mudas de eucalipto sob diferentes lâminas de irrigação. Rev Bras Agric Irrigada. 2019;13(1):3169-3179, doi: 10.7127/rbai.v13n100833.

11. Carvalho RP, Cruz MCM, Martins LM. Frequência de irrigação utilizando polímero hidroabsorvente na produção de mudas de maracujazeiro-amarelo. Rev Bras Frutic. 35(2):518-526, doi: 10.1590/S010029452013000200022.

12. Navroski MC, Araújo MM, Cunha F, Berghetti ALP, Pereira, MO. Influência do polímero hidroretentor na sobrevivência de mudas de Eucalyptus dunnii sob diferentes manejos hídricos. Rev Nativa. 2014;2(2):108-113, doi: 10.31413/nativa.v2i2.1571.

13. Navroski MC, Araújo MM, Rininger LRS, Muniz MFB, Pereira MO. Influência do hidrogel no crescimento e no teor de nutrientes das mudas de Eucalyptus dunnii. Floresta. 2015 Abr;45(2):315-328, doi: 10.5380/rf.v45i2.34411.

14. Jorge MHA, Melo RAC, Silva J, Butruille NMS, Oliveira CR, Borges SRS. Uso de hidrogel nanocompósito na produção de mudas de tomate e pimentão. Brasília (DF): Embrapa - Circular técnica 167; 2019. $22 \mathrm{p}$.

15. Nomur M, Pereira Filho JM, Costa EM, Pereira LS, Ventura MVA. Avaliação de diferentes quantidades de hidrogel na produção de mudas de mamão Papaya. Ipê Agron J. 2019;3(1):19-25, doi: 10.37951/25956906.2019v3i1.4320.

16. Silva C, Cechin NF. Manejo da irrigação na produção de mudas de Pinus taeda L. em viveiro florestal. Anais do Salão Internacional de Ensino, Pesquisa e Extensão da UNIPAMPA. 2020 Mar;11(2).

17. Ribeiro RM, Tessarolo G, Soares TN, Teixeira IR, Nabout JC. Global warming decreases the morphological traits of germination and environmental suitability of Dipteryx alata (Fabaceae) in Brazilian Cerrado. Acta Bot Bras. 2019;33(3):446-453, doi: 10.1590/0102-33062018abb0288.

18. Silva FA, Almeida Neto IP, Fernandes PD, Dias MS, Brito MEB, Lima AM. Ecofisiologia de mudas de pinheira (Annona squamosa L.) sob doses de esterco bovino e lâminas de irrigação. Res Soc Develop. 2020;9(7):1-18, doi: 10.33448/rsd-v9i7.4175.

19. Oliveira HFE, Xavier PS, Mesquita M, Campos HM, Salomão L, Vale LSR. Desenvolvimento inicial de mudas de mogno africano em função de substratos e lâminas de irrigação. Braz J Develop. 2020;6(4):20475-20482, doi: 10.34117/bjdv6n4-283.

20. Fonseca L, Jacobson TKB, Ogata RS, Solari RAF, Ribeiro RJC. Viabilidade do Hidrogel na Recuperação de Cerrado sensu stricto com Espécies Nativas. Floresta e Ambiente. 2017;24:1-8, doi: 10.1590/21798087.022716.

21. Putti FF, Gabriel Filho LRA, Cremasco CP, Silva Júnior JF. Água tratada magneticamente para irrigação: efeitos na produção e eficiência do uso da água na cultura da cenoura (Daucus carota L.). Rev Colomb Ciên Hort. 2018;12(2):447-455, doi: 10.17584/rcch.2018v12i2.7560. 
22. Maheshwari BL, Grewal HS. Magnetic treatment of irrigation water: Its effects on vegetable crop yield and water productivity. Agric Water Manag. 2009;96:1229-1236, doi: 10.1016/j.agwat.2009.03.016.

23. Suredran U, Sandeep O, Joseph EJ. The impacts of magnetic treatment of irrigation water on plant, water and soil characteristics. Agric Water Manag. 2016 Dec;178:21-29, doi: 10.1016/j.agwat.2016.08.016

24. Zúñiga O, Benavides JA, Ospina-Salazar DI, Jiménez CO, Gutiérrez MA. Tratamiento magnético de agua de Riego y semillas en agricultura. Ingeniería y Competitividad. 2016;18(2):217-232, doi: 10.25100/iyc.v18i2.2170.

25. Mendes JPP, Verssiani MAS, Amaral AM, Valadão GM. Calibração de sonda de baixo custo para monitorar umidade em substrato comercial. In: Anais do VII Congresso Virtual de Agronomia [Internet]; 30 Jun-4 Jul 2020. [São Paulo]: Covinbra; 2020 [citado em 8 Dez 2020]. Disponível em: https://artigosconvibra.s3.amazonaws.com/artigo_17245_2020023412.pdf.

26. Gomes FHF, Cunha FN, Lopes Filho LC, Vidal VM, Soares FAL, Teixeira MB. Rev Bras Agric Irrigada. 2017;11(4):1509-1516, doi: 10.7127/rbai.v11n400605.

27. Dickson A, Leaf AL, Hosner JF. Quality appraisal of white spruce and white pine seedling stock in nurseries. Forest Chronicle. 1960;36:10-13, doi: 10.5558/tfc36010-1.

28. Ferreira DF. Sisvar: a guide for its bootstrap procedures in multiple comparisons. Ciênc Agrotec. 2014;38(2):109-112, doi: 10.1590/S1413-70542014000200001.

29. Lopes NF, Lima MGS. Fisiologia da produção. Viçosa: UFV; 2015. 492 p.

30. Honorio ABM, Lopes MBS, Siebeneichler SC, Souza CM, Leal TCAB. Análise de crescimento e parâmetros fisiológicos em mudas de Dipteryx alata Vogel. Pesq Apl Agrotecnol. 2019 Jan,12(1):41-52, doi: 10.5935/PAeT.V12.N1.04.

31. Navroski MC, Araújo MM, Pereira MO, Fior CS. Influência do polímero hidroretentor nas características do substrato comercial para produção de mudas florestais. Interciencia. 2016 Mai,41(5):357-361.

32. Taiz L, Zeiger E, Moller IM, Murphy A. Fisiologia e desenvolvimento vegetal. $6^{\mathrm{a}}$ ed. Porto Alegre: ArtMed; 2017. 888 p.

33. Shahin M. M, Mashhour A. M. A, A bd-Elhady ESE. Effect of magnetized irrigation water and seeds on some water properties, growth parameter and yield productivity of cucumber plants. Current Sci Int. 2016 Apr;(2):152-164.

34. Monteiro Neto JLL, Araújo WF, Chagas EA, Siqueira HS, Oliveira GA, Rodriguez CA. Hydrogels in brazilian agriculture. Rev Agro@mbiente On-line. 2017 Out,11(4):347-360, doi: 10.18227/19828470ragro.v11i4.4130.

35. Hasan MM, Alharby HF, Uddin MN, Ali MA, Anwar Y, Fang XW, Hakeen KR, Alzahrani Y, Hajar AS. Magnetized water confers drought stress tolerance in moringa biotype via modulation of growth, gas exchange, lipid peroxidation and antioxidant activity. Polish J Environm Studies. 2020;29(2):1625-1636, doi: $10.15244 /$ pjoes/110347.

36. Matos FS, Freitas IAS, Santos LVB, Venâncio DG, Silveira PS. Initial growth of Dipteryx alata plants under water deficit. Rev Árvore. 2012;42(1);1-8, doi: 10.1590/1806-90882018000100003.

37. Souza LF. Contribuição de componentes morfoanatômicos, hidráulicos, bioquímicos e hormonais na aclimatação a múltiplos fatores de estresses em plantas de Dipteryx alata [dissertação]. Rio Verde (GO): Instituto Federal Goiano - Campus Rio Verde; 2019. 88 p.

38. Alves RDFB. Memória à seca no cerrado: aclimatação diferencial do baru (Dipteryx alata Vogel) [dissertação]. Rio Verde (GO): Instituto Federal Goiano - Campus Rio Verde; 2018. 48 p.

39. Sousa GTO, Azevedo GB, Sousa JRL, Mews CL, Souza AM. Incorporação de polímero hidroretentor no substrato de produção de mudas de Anadenanthera peregrina (L.) SPEG. Encicl Biosfera. 2013;9(16):1270-1278.

40. Cruz FRS, Andrade LA, Feitosa RC. Produção de mudas de umbuzeiro (Spondias tuberosa Arruda Câmara) em diferentes substratos e tamanho de recipientes. Ciência Florestal. 2016 Mar;26(1):69-80, doi: 10.5902/1980509821092.

41. Pinho EKC, Lopes ANK, Silva ABV, Vilar FCM, Reis RGE. Substratos e tamanhos de recipiente na produção de mudas de baruzeiro (Dipteryx alata Vog.). Ciência Agrícola. 2018;16(1):11-19.

42. Vendrulosco EP, Campos LFC, Seleguini A. Volume de tubetes e tipos de sementes para produção de mudas de jabuticabeira. Sci Agraria Paranaensis. 2017 Out;16(4):485-489, doi: 10.18188/19831471/sap.v16n4p485-489. 